\title{
Demographic Transition in Morocco: an application of Easterlin-Crimmins's model using DHS data
}

\author{
Lucia Ferrone \\ Economics Ph.D. \\ Department of Economics and Management, University of Florence \\ Via delle Pandette 9, 50127 Firenze (Italy) \\ Tel.: (Office) +39 055 2759037, (Mobile) +39 3284055407 \\ Email: lucia.ferrone@unifi.it
}

\begin{abstract}
The aim of this study is to shed some light on the dynamics of fertility reduction in the MENA region, analyzing both proximate and latent fertility determinants: DHS data for Morocco from the 2004 round were hence used for this purpose. The main idea behind this application is that the key variable in fertility transition is contraception prevalence and use. The Easterlin-Crimmins method (1985) is a two-stage model of supply and demand. There are two endogenous variables: number of born children (B), and contraception use $(U)$, while the exogenous ones are the costs of regulation, the demand for children, and the proximate determinants of fertility. Results show that contraception is, in fact, the key factor and determinant in fertility transition: ensuring access to contraception is therefore fundamental in reaching the final stage of the transition
\end{abstract}

Keywords: Morocco; fertility; contraception

\section{Résumé}

L'objectif de cette étude est de faire la lumière sur la dynamique de réduction de la fécondité dans la région MENA, en analysant les déterminants de la fécondité à la fois immédiates et latente: données de l'EDS du 2004 pour le Maroc ont donc été utilisés à cette fin. L'idée principale derrière cette application est que la variable clé dans la transition de la fécondité est la prévalence et l'utilisation de la contraception. La méthode Easterlin-Crimmins (1985) est un modèle en deux étages de l'offre et de la demande. Il ya deux variables endogènes: nombre d'enfants nés $(B)$, et l'utilisation de la contraception $(U)$, tandis que les exogènes sont les coûts de la réglementation, la demande pour les enfants et les déterminants proches de la fécondité. Les résultats montrent que la contraception est, en fait, le facteur clé et le principal déterminant de la transition de la fécondité: assurer l'accès à la contraception est donc fondamentale pour atteindre la phase finale de la transition.

Mots clé: Maroc; fécondité; contraception

\section{Introduction}

The Demographic Transition of south Mediterranean countries is of particular interest for the Northern shore and European countries. More so, as in recent years it appeared to be slowing, with the Total Fertility Rate for North Africa countries still set roughly around 2,5 children per woman (UN Population Division) from the beginning of the $21^{\text {st }}$ century. The aim of this study is to shed some light on the dynamics of fertility reduction in the region, analyzing both proximate and latent fertility determinants. DHS data for Morocco from the 2004 round were hence used for this purpose. The main idea behind this application is that the key variable in fertility transition is contraception prevalence and use. The Easterlin-Crimmins method (1985) is a two-stage model of supply and demand. There are two endogenous variables: number of born children (B), and contraception use $(U)$, while the exogenous ones are the costs of regulation, the demand for children, and the proximate determinants of fertility. The first stage estimates contraception (U), using supply and demand of children as predictors, with a tobit regression. The second stage estimates the number of born children (B), using all proximate determinants of fertility and the predicted values of $U(\hat{U})$. The sample consists of women who at the 
time of the interview had at least two children. Results show that contraception is, in fact, the key factor and determinant in fertility transition. All the other proximate determinants have the expected effects. As a robustness check, a TSLS was also estimated, as well as a different specification of the $U$ variable: in each case the results are confirmed. Additional regressions were estimated on the proximate determinants to take into account the effects of latent determinants of fertility: socioeconomic status, education and proxies for cultural attitude.

\section{Literature Review and Theoretical \\ Framework}

The study of the demographic transition trace back to Notestein's (1945) work, who was the first to notice and describe the process of drastic fall in fertility in modern western societies. But it isn't until Becker's (1960) influential work that reproductive behaviour is analyzed under economic light.

For the purpose of this study, the relevant strand of literature is the one tracing back to Bongaarts (1978), who indentifies eight proximate determinants of fertility, which he groups in three principal categories: exposition factors, deliberate birth control and factors influencing couples' natural fertility. This approach permits to disentangle the various aspects influencing fertility. The EasterlinCrimmins model (1985) features one additional step, with respect to Bongaarts, which is the use of a demand-supply model, and the costs of regulation. Thus, contraception becomes the key of the model: it is the link between demand and supply of children. Demand of children is identified by the number of desired children, and it is the one part of the model more heavily influenced by socio-economic factors. Supply, on the other hand, is the couple natural fertility, without regulation, and it is influenced by the proximate determinants.

More recently, while the literature has found constant evidence of the negative impact of socioeconomic determinants on fertility (Vignoli et al. 2008; D'Addato 2006), thus supporting Becker's early model and evidence coming from developed countries, there is also a constant evidence, for developing countries, of the central role of contraception and family planning (McNay et al. 2003).

As the demographic transition has had a common pattern in western societies, in recent years there has been a concern about the ongoing process in developing countries: in particular, countries of the south-eastern shore of the Mediterranean sea seemed to be stuck at a relatively high fertility level. What became clear is that economic improvement doesn't lead, automatically, to a lower fertility and on the contrary, a hard economic environment can lead to a low fertility: how much this changes will be structural or temporary, is still a debated issue (EIZeini 2009). Furthermore, cultural context is crucial in understanding the third and final part of the demographic transition (Courbage 1999).

\section{Data and Methods}

Data for this study were derived from the DHS survey of 2004 , which was originally of 16,768 women. In order to estimate the model the sample was restricted to women who had at least two children at the time of the interview, who had no child before marriage and who were currently in union: it's a sample of 6,496 observations with an average fertility rate of 4.36 .

The Easterlin and Crimmins model is a three stage model: I- Remote determinants influence regulation costs, supply and demand, 2 - The latter three influence contraception and 3- Contraception, along with the other proximate determinants, influences fertility.

Hence the first stage equation, estimating contraception $(U)$, is as follows:

$$
U=\lambda_{0}+\sum_{i=1}^{7} \lambda_{i} X_{i}^{\prime}-\delta C d+\gamma R C+\mu
$$

Where $\mathrm{Cd}$ is demand for children and RC is regulation cost, while children supply is constructed as the product between natural fertility and children survival rate, as follows:

$$
C n=\alpha_{0}+\sum_{i=1}^{7} \alpha_{i} X_{i}\left(1-X_{7}\right)
$$

Where $X_{7}$ is infant mortality while $X_{i}$ are the proximate determinants.

The first stage is estimated using Tobit regression because the dependant variable $U$ is continuous and truncated to the left. The second stage estimates the number of born children $B$ using the estimated values of $\mathrm{U}$ :

$$
B=\alpha_{0}+\sum_{i=1}^{7} \alpha_{i} X_{i}+\alpha_{8} \hat{U}+\epsilon
$$

The second stage was estimated using OLS following Easterlin and Crimmins themselves. Furthermore for the first stage it was also estimated a different specification of $U$, defining it as a dummy variable that takes value $I$ if the woman ever used contraception, 0 otherwise. This specification has been estimated with a Logit model: 


$$
\operatorname{Pr}(U=1)=F\left(\alpha_{0}+\sum_{i=1}^{7} \alpha_{i} X_{i}\left(1-X_{7}\right)-\delta C d+\gamma R C\right)
$$

The proximate determinants are: the duration of the union $\left(X_{1}\right)$, the duration of the first interval between births $\left(X_{2}\right)$ and the second $\left(X_{3}\right)$, woman fertility $\left(X_{4}\right)$, length of breast feeding $\left(X_{5}\right)$, interrupted pregnancies $\left(X_{6}\right)$ and infant mortality $\left(X_{7}\right)$.

The variable $X_{4}$ is constructed from the variable of exposure to pregnancy from the DHS dataset. A different specification of this variable didn't give any different result.

The demand for children $(\mathrm{Cd})$ is derived from the question about the ideal number of children, even though it can be a biased measure (Casterline and El-Zeini 2007).

The proximate determinants which are expected to have a positive relation with $U$ are $X_{1}, X_{4}$ and $X_{7}$, because these variables influence positively natural fertility and thus rise the motivation for the use of contraception. On the other hand $X_{2}, X_{3}, X_{5}$ and $X_{6}$ should have a negative relationship.

Regulation costs are accounted for by the number of methods known by the respondent (MK): the more methods known, the less cost of regulation so a positive relation between $M K$ and $U$ is expected.

\section{Results}

Table I reports the results for the first stage of the model with the two different specifications, as we can see the coefficients are mostly significant and have the expected sign. The only one not significant is $X_{6}$, interrupted pregnancies: the effect of this particular variable it's not obvious to understand and it can be biased.

\section{Table I: First Stage Regression on U}

\begin{tabular}{|c|c|c|}
\hline Independent Variables & $\begin{array}{l}\text { Tobit Model } \\
U=\text { continuous }\end{array}$ & $\begin{array}{l}\text { Logit Model } \\
U=\text { dummy }\end{array}$ \\
\hline \multirow[t]{2}{*}{ Union duration (XI) } & $10.0774 * * *$ & $0.0217^{*}$ \\
\hline & $(0.1069)$ & $(0.0110)$ \\
\hline \multirow[t]{2}{*}{ First birth interval (X2) } & $-0.7772 * * *$ & $-0.0148 * * *$ \\
\hline & $(0.0346)$ & $(0.0027)$ \\
\hline \multirow[t]{2}{*}{ Second Interval (X3) } & $-0.1366 *$ & $-0.0132 * *$ \\
\hline & $(0.0620)$ & $(0.0042)$ \\
\hline \multirow[t]{2}{*}{ Natural fertility (X4) } & $41.6476 * * *$ & $2.8670 * * *$ \\
\hline & $(2.8809)$ & $(0.1884)$ \\
\hline \multirow[t]{2}{*}{ Breastfeeding (X5) } & $-0.1949 *$ & $-0.0308^{* * *}$ \\
\hline & $(0.0963)$ & $(0.0058)$ \\
\hline \multirow[t]{2}{*}{ Interrupted pregnancies (X6) } & -0.6600 & 0.0483 \\
\hline & $(1.5448)$ & $(0.1638)$ \\
\hline \multirow[t]{2}{*}{ Infant Motality (X7) } & $192.0199 * * *$ & 0.0449 \\
\hline & $(14.1006)$ & $(0.9728)$ \\
\hline \multirow[t]{2}{*}{$\times 7^{\wedge} 2$} & $-125.4333 * * *$ & -3.1575 \\
\hline & $(29.0820)$ & $(1.6 \mid 12)$ \\
\hline \multirow[t]{2}{*}{ Methods Known (RC) } & $9.0983277^{* * *}$ & $0.4518 * * *$ \\
\hline & $(0.4836)$ & $(0.0350)$ \\
\hline \multirow[t]{2}{*}{$C d$} & $-3.7406 * * *$ & $-0.1487 * * *$ \\
\hline & $(0.4363)$ & $(0.03 \mid 4)$ \\
\hline \multirow[t]{2}{*}{ Constant } & -74.6|| $4^{* * *}$ & -0.3480 \\
\hline & $(5.9249)$ & $(0.4094)$ \\
\hline
\end{tabular}

S.E. in parenthesis $*=p<0.05,{ }^{*} *=p<0.01 * * *=p<0.00$ I 
The Logit model shows less significant coefficients but the dependent variable is less precise in capturing contraception use. As we can see regulation costs have a strong and significant relationship with $U$, while demand for children has a strongly negative one.

For the second stage we expect $B$, the number of children, to be positively correlated with $X_{1}, X_{4}$ and $X_{7}$, while it should be negatively correlated with $U$, $X_{2}, X_{3}, X_{5}$ and $X_{6}$. Results are shown in Table 2

Table 2: Second Stage Regression on B

\begin{tabular}{lcc}
\hline Independent Variables & Tobit Model & Logit Model \\
\hline Estimated contraception Û & $0.0216^{* * *}$ & $-3.1542 * * *$
\end{tabular}

$(0.00 \mathrm{II}) \quad(0.328 \mathrm{II})$

Union duration $(\mathrm{XI})$

$$
\begin{array}{rr}
0.3937 * * * & 0.19737355 * * * \\
(0.0109) & (0.0027)
\end{array}
$$

First birth interval $(X 2) \quad 0.0330 * * * \quad-0.0194 * * *$

$(0.0013) \quad(0.0009)$

Second Interval (X3) $\quad 0.0074 * * * \quad-0.0077 * * *$

$(0.0018) \quad(0.0016)$

Natural fertility $(X 4) \quad$ I.1676*** $\quad 0.7674 * * *$

$(0.0962) \quad(0.0956)$

Breastfeeding (X5) $\quad 0.0175 * * * \quad-0.0222 * * *$

$(0.0024) \quad(0.0022)$

Interrupted pregnancies (X6) $\quad-0.0753 \quad-0.0777$

$(0.0449) \quad(0.0413)$

Infant Motality (X7)

$2.2786 * * *$

$3.0638^{* * * *}$

0.1863

$(0.1679)$

Constant

I.3105*** 4.2446***

0.1236

$(0.2992)$

\begin{tabular}{lll}
\hline Adj. $R^{2}$ & 0.5809 & 0.5542
\end{tabular}

S.E. in parenthesis $*=p<0.05,{ }^{*} *=p<0.01 * * *=p<0.00$ I

All the coefficients have the expected sign and are strongly significant. As a robustness check, a two-stage least squares on $B$ with $U$ as endogenous variable was also estimated: results are shown in Table 3.
Table 3: TSLS Estimate with $\mathbf{U}$ endogenous.

\begin{tabular}{|c|c|}
\hline Contraception (Û) & $\begin{array}{r}-0.0305^{* * *} \\
(0.0021)\end{array}$ \\
\hline Union duration $(\mathrm{XI})$ & $\begin{array}{r}0.4779 * * * \\
(0.0209)\end{array}$ \\
\hline First birth interval $(X 2)$ & $\begin{array}{r}-0.0392 * * * \\
(0.002 \mathrm{I})\end{array}$ \\
\hline Second Interval (X3) & $\begin{array}{r}-0.0073^{*} \\
(0.0036)\end{array}$ \\
\hline Natural fertility (X4) & $\begin{array}{r}\text { I.5104*** } \\
(0.1840)\end{array}$ \\
\hline Breastfeeding (X5) & $\begin{array}{r}-0.0179 * * * \\
(0.0029)\end{array}$ \\
\hline Interrupted pregnancies (X6 & $\begin{array}{r}-0.0589 \\
(0.0556)\end{array}$ \\
\hline Infant Motality (X7) & $\begin{array}{r}\text { I.8628*** } \\
(0.2790)\end{array}$ \\
\hline Constant & $\begin{array}{r}\text { I.2240*** } \\
(0.2112)\end{array}$ \\
\hline
\end{tabular}

Independent Variables

S.E. in parenthesis ${ }^{*}=p<0.05,{ }^{* *}=p<0.0$ I ${ }^{* * *}=p<0.00$ I

As we can see there are no differences in results which are therefore confirmed. The only not significant variable remains the interrupted pregnancies $\mathrm{X}_{6}$ that was already discussed.

\section{Discussion}

Easterlin and Crimmins model is confirmed as a solid and reliable model to explain fertility transition: proximate determinants explain a great part of fertility variability and the specific variables of the model RC and Cd have a good predictive value as well.

Issues remain regarding the construction of some variables, as the 'ideal' number of children or the natural fertility of the woman. Also, there are possible issues regarding the causality direction and possible endogeneity, even if the two stage procedure, which replicates an Instrumental Variables model, should be able to address them.

To have a clearer understanding of the causality direction between variables a longitudinal dataset would be needed. 
The last part of the model should be to establish the correlation between the Easterlin-Crimmins variables and remote determinants such as socioeconomics ones: some OLS regressions where estimated using some of the socioeconomic variables available in the DHS dataset. Among the most significant ones are education level and urban residence, as expected, and a measure of female empowerment based on the question, present in the dataset, about the reason a woman can have to refuse sexual intercourse to her husband. Nonetheless this regressions are very raw and demand further investigation and the results are not presented here. An important topic to investigate further would be the relevance of cultural attitude on the proximate determinants of fertility, especially the use of contraception.

\section{Conclusions}

This work confirms that contraception has a key role in both understanding and promoting fertility transition in developing countries. While we cannot rule out the importance of more remote determinants, among which cultural ones, it is crucial that governments promote and maintain, where it already exists, a widespread access to and knowledge of contraception and general reproductive health.

Further investigation is needed but it seems clear that lowering the cost of regulation and enhancing the knowledge of modern contraception methods is the key to a lower fertility. It is also important to promote the use of contraception to directly prevent pregnancies and not only as a mean to delay them, as it is often the case in MENA countries.

It is clear that the role of governments and institutions in developing countries is far from being irrelevant to the completion of demographic transition.

\section{References}

Abdelkhalek T., Ajbilou A. \& Fazouane A. (2000) Pauvreté, besoins de base et comportements démographiques au Maroc, Bulletin Économique et Social du Maroc, n. 159, pp. 4I-6I

Angeli A., Grassini L. \& Salvini S. (1992) 'Family Planning and Modernization, A study of the Determintas of fertilty in Peru and Colombia' In: Proceedings of the conference 'Chaire Quetelet', Université Catholique de Louvain-la-Neuve: Institut de Démographie

Becker G. S. (1960) 'An economic analysis of fertility' In: Demographic and economic change in developed countries, pp. 209-231, Princeton: National Bureau of Economic research
Berer M. (2005) 'Implementing ICPD: What's Happening in Countries' Reproductive Health Matters, Vol. 13 (26), pp. 6-10

Bongaarts J. (1978) 'A framework for analyzing the proximate determinants of fertility' Population and Development Review, Vol 4 (I), pp. 105-I 32

Bongaarts J. (1987) 'The Proximate Determinants of Exceptionally High Fertility' Population and Development Review, Vol. 13 (I), pp. 133-139

Bongaarts J. (2006) 'The Causes of Stalling Fertility Transitions' Studies in Family Planning, Vol. 37 (I), pp. $1-16$

Brown G.F. (2007) 'Morocco: First steps in family planning' In: The global family planning revolution: three decades of population policies and programs, pp. 7I-82, Washington, D.C.: The World Bank

Bryant J. (2007) 'Theories of Fertility Decline and the Evidence from Development Indicators', Population and Development Review, Vol. 33 (I), pp. 10I-127

Casterline J.B. \& El-Zeini L.O. (2007) 'The estimation of unwanted fertility', Demography, Vol. 44 (4), pp. 729-745

Courbage Y. (1999) 'Economic and Political Issues of Fertility Transition in the Arab World-Answers and Open Questions' Population and Environment, Vol. 20 (4), pp. 353-380

Curtis S.L. \& Westoff C.F. (1996) 'Intention to Use Contraceptives and Subsequent Contraceptive Behavior in Morocco' Studies in Family Planning, Vol. 27 (5), pp. 239-250

D'Addato A.V. (2006) 'Progression to third birth in Morocco in the context of fertility transition' Demographic Research, Vol. 15 (19), pp. 517-536

D'Addato A.V., Vignoli D. \& Yavuz S. (2008) 'Towards smaller family size in Egypt, Morocco and Turkey: Overall change over time or socioeconomic compositional effect?' Population Review Vol 47 (I), pp. 25-44

Easterlin R.A. \& Crimmins E. M. (1985) The fertility revolution. A Supply-Demand Analysis, Chicago: The University of Chicago press

Eltigani E.E. (2000) 'Changes in family-building patterns in Egypt and Morocco: a comparative analysis' International Family Planning Perspectives, Vol. 26 (2), pp. 73-78

Eltigani E.E., 200I 'Childbearing in five Arab countries' Studies in Family Planning, Vol. 32 (I), pp. 17-24

Eltigani E.E. (2005) 'Fertility Translation in Arab Countries: a Re-evaluation' Journal of Population Research, Vol. 22, No. 2, pp. 163-183 
Fargues P. (1993) 'Demography and Politics in the Arab World' Population: An English Selection, Vol. 5, pp. I-20

Fargues P. (2005) 'Women in Arab Countries: Challenging the Patriarchal System?' Reproductive Health Matters, Vol. 13 (26), pp. 43-48

Fargues P. (2006) The demographic benefit of international migration: hypothesis and application to Middle Eastern and North African contexts World Bank Policy Research Working Paper n. 4050

Gwatkin D.R. e al. (2007) Socio-economic differences in health, nutrition, and population. Morocco, 1992, 2003/04 Human Development Network, Washington, D.C: The World Bank

Kalwij A. S. (2000) 'The Effects of Female Employment Status on the Presence and Number of Children' Journal of Population Economics, Vol. 13 (2), pp. $221-239$

McNay K., Arokiasamy P. \& Cassen R.H. (2003) 'Why Are Uneducated Women in India Using Contraception? A Multilevel Analysis' Population Studies, Vol. 57 (I), pp. 2I-40

Notestein F.W. (1936) 'Class differences in fertility' In: Annals of the American Academy of political and social science, Vol. 188, pp. 26-36
Notestein F.W. (1945) 'Population: the long view' In: Food for the World, Theodore W. Shultz, The University of Chicago Press

Obermeyer C.M., 2000 'Sexuality in Morocco: changing context and contested domain' Culture, Health \& Sexuality, Vol. 2 (3), pp. 239-254

Raftery A.E. \& Lewis S.M. (1995) 'Demand or Ideation? Evidence from the Iranian Marital fertility Decline' Demography, 32 (2), pp. I59- I82

Shakour B. (2008) Demographic change in the Arab countries: prospects for the future Summary of social policies, Beirut, Lebanon: Economic and Social Commission for Western Asia

Shultz T.W. (1974) Economics of the Family. Marriage, Children and Human Capital, National Bureau of Economic Research: The University of Chicago Press

Tabutin D. \& Schoumaker B., 2005. 'The demography of the Arab world and the Middle East from the 1950s to the 2000s' Population, Vol. 60 (5-6), pp.505-6I6

Townsend J.G. (199I) 'Towards a regional geography of gender' The Geographical Journal, Vol. 157 (I), pp. 25-35 